\title{
La época capitalista*
}

\author{
William H. Sewell Jr. \\ Traducción del francés al español de Jessica Montaño Oliveros \\ Universidad de Antioquia, Medellín, Colombia \\ jmontanooliveros@gmail.com
}

\section{RESUMEN}

Este artículo defiende la idea de que el capitalismo debe entenderse como un fenómeno de época, es decir, como un modo de vida históricamente específico y temporalmente limitado, cuyas dinámicas sociales y temporales, que no están destinadas a durar para siempre, lo desligan de las épocas históricas anteriores y futuras. La característica más común del capitalismo (un crecimiento económico secular prolongado en términos de capital per cápita) ha traído grandes beneficios a la especie humana, no solo al mejorar el bienestar económico, sino al dotar a las personas con cuerpos más grandes, más fuertes y más resistentes; además de incrementar de manera radical la esperanza de vida. También hizo posible un sorprendente aumento de los poderes sociales en cuanto a lo tecnológico, lo educativo y lo científico. Experimentar un crecimiento económico prolongado ha dado lugar a un sentido particular del tiempo, abierto y progresivo, que ha hecho posible la consciencia histórica moderna. Entretanto, la constante mercantilización de las relaciones sociales dentro del capitalismo ha permitido liberar a los individuos de la dominación basada en el estatus personal, al tiempo que los somete a formas más abstractas de dominación. La destrucción creativa, mecanismo esencial del capitalismo para producir un crecimiento económico prolongado, también ha generado un patrón cíclico imposible de manejar, lleno de expansiones y crisis, que ha creado nuevas formas de inseguridad, a la vez que tiende a sacar a las personas de la pobreza extrema. Además, el desarrollo capitalista siempre ha sido desigual a nivel espacial. Finalmente, hay razones para creer que la era capitalista está llegando a su fin. La forma que tome la era poscapitalista dependerá de la manera en que usemos colectivamente los poderes sociales que la era capitalista produjo - la ciencia y la tecnología, obviamente-, pero también la consciencia histórica crítica que yace en el corazón de la historia de las ciencias sociales.

Palabras clave: historia; capitalismo; época; consciencia histórica; crecimiento.

Cómo citar: Sewell Jr., W. H. (2021). La época capitalista. (J. Montaño, trad.). Ciencias Sociales y Educación, 10(19), 351-364. https://doi.org/10.22395/csye.v10n19a11

Traducción realizada por Jessica Montaño Oliveros del texto de Sewell (2019).

Agradecemos a la revista Tracés. Revue de Sciences humaines poner a disposición sus artículos para su publicación en otros idiomas. Nota del editor.

Recibido: 4 de noviembre de 2020.

Aprobado: 10 de enero de 2021. 


\section{Introducción}

Fue solo hasta hace poco que me dediqué seriamente al tema del capitalismo. Durante la mayor parte de mi carrera intelectual estudié la historia de las revoluciones, particularmente las sucedidas en Francia en 1789, 1830 y 1848 (Sewell, $1980,1994)$. Trabajar estos acontecimientos, a la vez contingentes y fundamentales que son las revoluciones, me llevó a ser muy crítico frente a las explicaciones deterministas y estructurales de las revoluciones y, más ampliamente, de la historia. En realidad, fuera del pequeño círculo de historiadores de Francia, es probable que me conozcan por mis esfuerzos por introducir una sensibilidad histórica de la temporalidad dentro de la teoría social. Tal como me he esforzado por exponer en mis escritos, la temporalidad social es contingente, fatídica, compleja, azarosa y heterogénea y, ciertamente, no es teleológica (Sewell, 2005).

Sin embargo, en tanto objeto de estudio histórico, el capitalismo plantea serios problemas frente a los argumentos que he desarrollado en el pasado; de hecho, se caracteriza por ciertas formas de temporalidad que había descartado en mis trabajos anteriores. Esto quiere decir que el capitalismo posee dinámicas temporales a largo plazo con una fuerte direccionalidad. Estas dinámicas complejas, presentes en el capitalismo desde hace al menos unos tres siglos, se manifiestan a través del crecimiento económico prolongado, la expansión geográfica constante y la mercantilización continua de las relaciones sociales. Del mismo modo, el capitalismo también está marcado por un ritmo temporal extraño y repetitivo, llamado ciclo económico ${ }^{1}$. Para resumir, el capitalismo parece ser una gran excepción a aquello que de manera prematura afirmé que era la "contingencia global" de la temporalidad social (Sewell, 2005, p. 120). Por eso, el capitalismo me resulta un objeto de estudio completamente fascinante.

Al final, sigo creyendo en la contingencia global de la temporalidad social y de las formas sociales. El capitalismo, tal como lo percibo, tiene dinámicas temporales a largo plazo muy restrictivas, pero lo cierto es que no es producto de ninguna ley transhistórica ni teleológica de desarrollo social; yo diría más bien que el capitalismo es un producto contingente $-\mathrm{y}$ temporal- de la historia. Apareció en un rincón del mundo muy particular y bajo unas circunstancias históricas muy específicas: en la parte noroccidental de Europa, en una época en la que los europeos acababan de establecer una dominación comercial y militar de los mares. Su surgimiento como sistema fue el resultado de una conjunción, que no se pudo haber previsto, entre los desarrollos en agricultura, comercio, industria, política y cultura durante los siglos XVI,

Mis esfuerzos por intentar darle un sentido a las temporalidades del capitalismo pueden encontrarse particularmente en Sewell $(2008,2012)$. 
XVII y XVIII2. Sin embargo, una vez establecido de manera contingente como sistema, el capitalismo generó una dinámica social única desde el punto de vista histórico, una ley particularmente poderosa y expansiva, que poco a poco abarcó y transformó el mundo entero con lo que parece haber sido una suerte de fatalidad. Si se mira desde los largos recorridos de la historia mundial y desde la mayoría de los procesos históricos comprendidos en la era capitalista, esta dinámica expansionista y supuestamente incontenible del capitalismo parece casi incomprensible.

\section{El capitalismo como fenómeno de época}

El surgimiento del capitalismo introdujo una nueva forma de temporalidad en la historia, y esto implica que deberíamos entender el capitalismo como el punto de partida de una nueva época en la aventura humana. Este modo de vida histórico que moldea la época y que llamamos capitalismo se centra, como no había sucedido antes, en la producción, el intercambio y el consumo de bienes. Pero el capitalismo no se reduce solo a un sistema económico, pues es un todo social complejo con formas políticas, psicologías, relaciones sociales y rasgos culturales específicos. Hasta ahora ha tenido una trayectoria histórica de tres a cuatro siglos, pero es poco probable que continúe de manera indefinida. En efecto, hay razones para pensar que la vida social, política y económica del planeta experimentará una transformación tal durante el próximo siglo, que nuestra progenie no vivirá ya en un mundo particularmente capitalista.

Un elemento fundamental para comprender la historia del capitalismo como fenómeno de época es que todos hemos tenido el privilegio - o la desdichade vivir bajo su vasta y aun así limitada influencia temporal y geográfica. Al escribir su historia, nos enfrentamos a un fenómeno que nos impregna y nos define como personas, como intelectuales, de muchas más maneras de las que somos capaces de asimilar. Como no se puede estar fuera del mundo que el capitalismo creó, para escribir sobre el capitalismo con cierto grado de objetividad se debe adquirir una consciencia crítica y reflexiva frente a nuestra inevitable participación en nuestro objeto de estudio.

Creo que conceptualizar el capitalismo como un fenómeno de época se aleja de la manera en que los economistas e historiadores económicos han pensado el capitalismo (al menos esa es la imagen que da el discurso económico a un forastero como yo). En economía, cuando se utiliza el término capitalismo, generalmente se hace de manera descriptiva, para referirse a un sistema económico que se caracteriza por la omnipresencia de los intercambios comerciales y por

La literatura que existe sobre los orígenes del capitalismo es amplia. Entre los trabajos que más influenciaron el mío cito a Arrighi (1994), Aston y Philpin (1985), de Vries (2008), Marx (1977; Postone, 1993), North y Thomas (1973), Wallerstein (1974) y Weber (2000). 
el predominio de la empresa privada. En historia económica, la historia del capitalismo es, en esencia, la del crecimiento económico moderno y se centra en relatar el paso gradual de instituciones malas a instituciones buenas. Según Douglas North (1981, 1990), las instituciones buenas son las que reducen los costos de transacción, aumentan los incentivos al intercambio y a la innovación tecnológica y organizacional; por eso son, evidentemente, la fuente del crecimiento. Desde esta perspectiva, la historia del capitalismo es fundamentalmente la de la supresión gradual de los obstáculos que se le presentan al crecimiento económico basado en el mercado. En el discurso económico, el crecimiento se plantea como un objetivo naturalizado de la vida económica y el capitalismo como la estructura económica, igualmente naturalizada, que permite lograr ese objetivo; así, la historia económica tiende a ser la historia de cómo se logra alcanzar este objetivo preestablecido.

\section{El crecimiento y sus límites}

Así pues, ¿cuáles son las dinámicas temporales únicas o destacables de la era capitalista? El crecimiento económico prolongado indefinidamente —aquello que Karl Marx llamó la ilimitada acumulación de capital- es, sin lugar a duda, la característica más notoria de la era capitalista. Es necesario reconocer qué tan nuevo es este tipo de crecimiento económico en la historia mundial. La historia está llena de ejemplos de lo que podría llamarse la prosperidad económica, en diferentes épocas y a lo largo de una gran variedad de lugares en todo el mundo. Por prosperidad económica me refiero a los episodios, a veces prolongados por uno o dos siglos, de crecimiento económico, sofisticación de los productos, agricultura intensiva y crecimiento demográfico. Sin embargo, en el siglo XVIII el crecimiento poblacional que caracterizó estos periodos terminó por igualar o sobrepasar todas las alzas en productividad, lo cual implicó un estancamiento o una disminución del ingreso per cápita3. Estos episodios de prosperidad económica deben diferenciarse claramente del crecimiento económico moderno en sentido estricto, es decir, del crecimiento prolongado e indefinido del ingreso real per cápita. En sentido estricto, el crecimiento económico, que comenzó en la economía del Atlántico en el siglo XVIII y se ha extendido — de manera muy desigual- por todo el mundo en los últimos tres siglos, no tiene precedentes históricos. Esta singularidad la confirma el hecho de que, desde principios de siglo XVIII, la población mundial casi se ha decuplicado y el ingreso mundial per cápita sigue creciendo. El crecimiento económico capitalista moderno dejó inoperantes los mecanismos maltusianos que siempre habían limitado el crecimiento de la población.

La enunciación clásica de este argumento la presenta Le Roy Ladurie (1974). 
En muchos aspectos, el crecimiento económico ha sido una verdadera bendición para el capitalismo. Ha mejorado enormemente la vida humana, de manera particularmente drástica durante el siglo XX. Robert Fogel y otros historiadores sociales han demostrado que las personas que hoy viven en los países más prósperos están mejor alimentadas, son más altas, más robustas, más fuertes, menos enfermas, capaces de trabajar más y viven mucho más tiempo que sus antepasados de los siglos XVIII o XIX. En otras palabras, la expansión del capitalismo transformó profundamente el propio ser físico de los humanos (Floud et al., 2011; Fogel, 2004). Y esta transformación no se limita solo a los países ricos. Incluso los ciudadanos de Haití, un país particularmente pobre, tienen actualmente una esperanza de vida de más de sesenta años. Además, en el capitalismo mundial contemporáneo, las tasas de alfabetización y los niveles de educación se han disparado y las capacidades humanas se han multiplicado, en gran medida, gracias a los avances tecnológicos y a la extracción de energía. Ciertamente, esta fantástica mejora de las condiciones de vida de la mayoría de los seres humanos debe verse en sí misma como un verdadero progreso.

Es apropiado aquí hacer oír la voz escéptica de Marx, quien también celebró el extraordinario estallido de productividad del capitalismo: en 1848, él y Engels declaran en el Manifiesto del partido comunista que "[e]n su dominación de apenas un siglo de duración, la burguesía ha creado fuerzas de dimensiones más colosales que las creadas por todas las generaciones anteriores conjuntamente" (Marx y Engels, 1962, p. 45). Pero Marx también era consciente del lado oculto y perverso de la prodigiosa creación de riqueza material del capitalismo. En definitiva, al igual que Max Weber (2000), Marx consideraba que la máquina de creación dinámica de riqueza del capitalismo era irracional, además de estar impulsada por la acumulación para la acumulación sin tener en cuenta sus consecuencias para los humanos. El argumento de Marx era que el capitalismo era esencialmente incapaz de preocuparse por la salud y el bienestar de su fuerza de trabajo, lo cual socavaría el sistema capitalista, lo llevaría a una crisis monumental y causaría su desmantelamiento a manos de la revolución proletaria.

Por supuesto, esta predicción no se cumplió. Pero en la actual era de la inminente catástrofe medioambiental, resulta particularmente pertinente el argumento de Marx sobre cómo la lógica misma de la competencia capitalista llevaría a los capitalistas a explotar a los trabajadores de manera tan despiadada, que terminarían por destruir la base del sistema capitalista. Ahora es bastante claro que buscar y replicar en todo el mundo un crecimiento económico cuya base sea el consumo intensivo de energía, crecimiento que produjo el auge del capitalismo de los últimos tres siglos, ha llevado a un grave y acelerado calentamiento global, a un aumento en el nivel del mar, a la desaparición masiva de especies y a una devastadora escasez de agua para el consumo y para la agricultura; en pocas 
palabras, ha llevado a un incalculable y potencialmente drástico deterioro de la vida para nuestros nietos y bisnietos. Sin embargo, las sociedades capitalistas contemporáneas han demostrado ser incapaces de afrontar esta amenaza a la existencia. Por lo general, los capitalistas se resisten a las políticas públicas que limitan esas amenazas medioambientales, pues incrementarían los costos y limitarían las ganancias. Por su parte, los consumidores están acostumbrados a una superabundancia de bienes y servicios atractivos o esperan que haya tal abundancia, por lo que se rehúsan siquiera a pensar en reducir el consumo para preservar el mundo para sus nietos. Y los políticos, que necesitan del capitalismo y de los consumidores para seguir en sus cargos, prefieren hacer tiempo o, de plano, negar abiertamente la innegable evidencia científica sobre el cambio climático global.

El sistema capitalista, que debe expandirse para sobrevivir, actualmente se contrapone -económica, política y culturalmente-a las condiciones del desarrollo futuro de la especie humana. Por este motivo afirmo que la época capitalista de la historia humana no continuará de manera indefinida. En el mejor de los escenarios futuros, se podrán usar las mejores herramientas que nos ha dado el capitalismo (ciencia y tecnología, alfabetización universal, igualdad social y un nuevo cuerpo humano más vigoroso y sano) para hacer de la Tierra un hogar estable y habitable —aunque seguramente más caliente- para muchos más humanos. El Antropoceno, que generó el capitalismo, debe ser compatible con una sociedad humana decente4. Pero el tiempo se acaba y actualmente es difícil reconocer las fuerzas sociales que podrán llevar a la especie humana a hacerle frente a las tareas colosales que se necesitan hoy. Para mí, la única postura política e intelectualmente plausible es una adaptación de la frase de Antonio Gramsci (1971): "pesimismo de la inteligencia, optimismo de la voluntad".

\section{La mercantilización y la dominación abstracta}

Junto al crecimiento económico prolongado, la era capitalista también trajo una mercantilización gradual y profunda de las relaciones sociales. Es evidente que los intercambios comerciales intervienen en una proporción cada vez mayor en el consumo de bienes y servicios de la población de las sociedades capitalistas. En las sociedades plenamente capitalistas, no es común que los individuos cultiven sus propios alimentos, tejan su propia tela, fabriquen sus propias herramientas u obtengan bienes o servicios a través del trueque o de un ritual de redistribución. Y más allá de esta mercantilización de todas las cosas, el capitalismo también mercantilizó el trabajo humano. En esencia, los salarios se universalizaron, todos los trabajos se hacen a cambio de dinero y los bienes y ser-

Para ampliar información sobre el desafío que implica el cambio climático para la investigación histórica, remitirse a Chakrabarty (2009). 
vicios se adquieren mediante la compra en el mercado. Por lo tanto, el trabajo, la actividad sensorial que ocupa la mayor parte de nuestra vida adulta cuando estamos despiertos, es una mercancía y, como cualquier mercancía, el trabajo se equipara, mediante el intercambio monetario universal, a otras mercancías cuyas cantidades fluctúan y se producen e intercambian en todo el mundo. Esto significa que nuestra propia actividad vital está sujeta a las fuerzas anónimas y abstractas que rigen la producción y el intercambio en el capitalismo, fuerzas cuyas leyes han intentado dominar durante mucho tiempo los economistas y otros científicos sociales — hasta ahora, hay que decirlo, sin mucho éxito-. Bajo el capitalismo, la humanidad está cada vez más sujeta a lo que Moishe Postone (1993) llamó “dominación social abstracta": nuestro bienestar, nuestras rutinas diarias, nuestras trayectorias de vida o el valor de nuestras capacidades y habilidades están determinados en gran medida por fuerzas "económicas" abstractas, anónimas y aparentemente objetivas que están fuera de nuestro control (incluidas las que nos llevan a la insostenibilidad medioambiental).

Si la dominación abstracta actúa sobre nosotros a través de fuerzas que parecen ciegas y mudas, también nos lleva más allá por medio de atractivos visuales y verbales que se presentan de manera abierta y locuaz, en una especie de autoabstracción voluntaria en forma de identidades mercantilizadas. Efectivamente, cada vez hablamos más del marketing personal. La dinámica de la moda, reforzada por la publicidad, transforma la búsqueda universal de estatus y reconocimiento en un deseo insaciable de nuevos productos que permitan autodefinirse. Basándome en mis propios estudios, puedo afirmar que la dinámica capitalista de la moda viene desde mucho tiempo atrás en la historia del capitalismo, se remonta al menos a principios del siglo XVIII, cuando los fabricantes de seda de Lyon comenzaron a cambiar sus diseños anualmente (Sewell, 2010). Hoy en día, vivimos en un mundo completamente saturado con publicidad, mercancías y marcas.

Esta cualidad abstracta de las relaciones sociales capitalistas también sirvió para liberarnos, de manera gradual, de las formas preestablecidas de dominación personal, jerárquica y comunitaria características de las sociedades precapitalistas. No es que los individuos que vivieron en sociedades precapitalistas no hayan estado bajo ningún dominio, sino que el dominio bajo el que viven los individuos en las sociedades capitalistas es muy diferente. De hecho, el proceso capitalista de abstracción moldeó nuestra personalidad como individuos aparentemente independientes y autodeterminados, capaces de adoptar, en principio, cierta postura crítica frente a las fuerzas y a las instituciones que los dominan. Al mismo tiempo, ese proceso hizo que la naturaleza de estas fuerzas e instituciones fuera cada vez más difícil de comprender y, aún más, difícil de desafiar. Por eso, el auge del capitalismo correspondió temporalmente al de 
las ciencias sociales que, luego de su aparición, intentaron explicar las formas y los procesos de la vida social en términos de fuerzas y estructuras sociales y abstractas, más que en términos de voluntad humana o divina.

El auge del capitalismo también correspondió temporalmente con el de la igualdad social, que establece una equivalencia formal entre los ciudadanos, más allá de las diferencias accidentales que puedan existir entre ellos en cuanto a capacidades, salud o prestigio social. Tal formulación tiene mucho sentido en un mundo social en el que los individuos se definen, no por formas intrínsecas de honor, sino por el intercambio de mercancías —incluyendo su trabajo—en un mercado anónimo. Para resumir, si bien el capitalismo desarrolló nuevas formas abstractas de dominación, este proceso de abstracción social también contribuyó al desarrollo de formas culturales —como las ciencias sociales y la idea de igualdad—, que sirven de base para una crítica de esa misma dominación.

\section{La experiencia temporal del capitalismo}

La sociedad capitalista también se diferencia de las estructuras sociales anteriores por sus formas y experiencias específicas en relación con el tiempo. Tanto los ritmos reales de la vida social como la manera en que se experimenta y conceptualiza el paso del tiempo son cualitativamente diferentes en la era capitalista frente a los periodos anteriores.

La omnipresente tendencia expansionista del capitalismo ha sido una gran fuente de nuevas formas de razonamiento temporal. Reinhart Koselleck (2002) afirma que, en el siglo XVIII, cuando comenzó el crecimiento económico capitalista, los intelectuales empezaron a pensarse como habitantes de un "nuevo tiempo", ese que comúnmente llamamos Modernidad y que en alemán se llama, de manera más simple y elocuente, Neuzeit. Esta concepción emergente de la temporalidad se vio marcada por una sensación de aceleración del tiempo histórico y una apertura del futuro, es decir, la idea de que el futuro sería cualitativamente diferente del presente en lugar de una repetición, reiteración o recombinación de lo que ya había tenido lugar. Se consideraba que el tiempo, más que ser una simple sucesión, incorporaba una dinámica intrínseca. Según una formulación bastante común, el tiempo se considera progresivo; así, por ejemplo, Diderot, filósofo francés del siglo XVIII, decidió no publicar numerosos trabajos literarios y filosóficos que sabía que escandalizarían a sus contemporáneos. Sin embargo, los siguió escribiendo, pues confiaba plenamente en que serían apreciados luego de su muerte, en una sociedad futura más ilustrada (Wilson, 1972).

Esta comprensión del tiempo como progresivo y abierto, cuyos principales rasgos compartimos con los pensadores del siglo XVIII, se basó en la experiencia 
del crecimiento económico del capitalismo temprano. Incluso si Diderot no vivió el tiempo suficiente para ver los colosales cambios tecnológicos que forjó la revolución industrial, vivió en una época en la que el crecimiento económico era palpable. Al vivir en París entre los años 1720 y 1780, experimentó una creciente proliferación de nuevos bienes de consumo, un notable crecimiento del comercio entre Europa y el resto del mundo, una proliferación de cafeterías y lugares de comercialización del ocio y un aumento de las ventas de material impreso -incluyendo las de su famosa Enciclopedia, que dirigió y sobre la que escribió varios artículos-. El propósito de la Enciclopedia de Diderot era expandir el pensamiento de la Ilustración, especialmente el mejoramiento de las técnicas, herramientas y prácticas que Diderot llamó las artes mecánicas y que nosotros llamaríamos industria. Diderot experimentó y ayudó a promover las expansivas tendencias del capitalismo temprano y la nueva comprensión de la temporalidad que este traía consigo.

\section{La creación destructiva y las temporalidades cíclicas}

El crecimiento económico y la correspondiente comprensión del tiempo como progresivo expresan, sin embargo, solo un aspecto de la temporalidad propia del capitalismo. El ciclo económico, que sigue siendo incontrolable a pesar de los esfuerzos de generaciones de economistas y banqueros centrales, es una característica temporal tan propia de la sociedad capitalista como el crecimiento económico prolongado indefinidamente. Esto es tan cierto hoy como lo fue cuando Schumpeter (1950) acuñó el término destrucción creativa, proceso del cual depende el crecimiento de la economía capitalista; así, la creación tiene lugar principalmente en períodos de recuperación y la destrucción en períodos de crisis. El crecimiento capitalista es esencialmente episódico y siempre está en crisis. El fenómeno de la destrucción creativa, que implica que las empresas, industrias y economías locales y nacionales nunca están libres de la amenaza devastadora de sus competidores, va acompañado de una poderosa sensación de inseguridad, de transitoriedad, de una potencial crisis que atenúa y contradice parcialmente la conciencia temporal progresiva tan característica de las sociedades capitalistas. De alguna manera siempre somos conscientes, para parafrasear a Marx y Engels (1962) y a Marshall Berman (1982), de que en las sociedades capitalistas "todo lo que es sólido" puede "desvanecerse" con facilidad.

Otro ritmo temporal característico del capitalismo reside en la desigualdad de su desarrollo espacial. Los impulsos creativos que alimentan el crecimiento se localizan necesariamente en industrias y lugares específicos - como Lancashire, la región del Ruhr, Detroit, Silicon Valley o Shenzhen-, mientras que otros lugares se estancan o incluso entran en recesión. Este proceso desigual de desarrollo ocurre en todos los niveles: al interior de las ciudades, 
entre ciudades y regiones, entre países y entre continentes ${ }^{5}$. Los efectos acumulativos de este desarrollo desigual han hecho que hoy diferentes regiones del mundo sean mucho más desiguales de lo que lo fueron en 1700, cuando los ingresos per cápita en China, India y Oriente Medio parecen haber sido casi equivalentes a los de Europa (Bourguignon y Morrison, 2002; Pomeranz, 2000). Sin embargo, los lugares más y menos favorecidos también se mueven a través del espacio y el tiempo según el ritmo impredecible de la destrucción creativa. De este modo, las regiones de Lancashire, Ruhr y Detroit, que habían experimentado un excepcional esplendor, ahora forman parte del Rust Belt mundial, mientras que China se fortalece cada vez más como contrincante de la dominación económica de Occidente. Para el capitalismo, este desarrollo espacial tremendamente desigual, con sus imprevisibles movimientos crecientes o decrecientes, implica un ritmo espaciotemporal esencial y constitutivo.

Este desarrollo espacial desigual también tiene una dimensión político-militar muy importante. El capitalismo, desde sus orígenes, se ha basado no solo en un comercio mundial, sino en las proyecciones mundiales del poder de los Estados - desde los buques de vela de la armada y los remotos puestos de comercio de la Compañía Neerlandesa de las Indias Orientales; hasta los Estados Unidos de hoy, con su marina mundial, su poder aéreo, sus fuerzas móviles terrestres, su red mundial de bases y aeródromos, junto con el poder blando de la ayuda internacional, los tratados internacionales y las organizaciones intergubernamentales-. Este poder político-militar se ha utilizado de manera constante, desde los inicios del capitalismo, para generarles ventajas económicas a los Estados poderosos - a través de todo tipo de mecanismos, desde tomarse el territorio hasta imponer relaciones comerciales desiguales o manipular los tipos de cambio y la deuda externa-. Del mismo modo, los países que obtienen ventajas económicas utilizan esa riqueza para aumentar su poder político y militar. La Europa occidental, que originalmente era el centro de la sociedad capitalista mundial, desde hace mucho tiempo ha estado dividida entre Estados rivales en guerra, y el desarrollo del comercio mundial desde el siglo XVI ha llevado estas hostilidades a los océanos y a costas distantes.

Giovanni Arrighi (1994) demostró que las fases de conflicto entre las grandes potencias corresponden a fases de evolución y gobernanza de la economía capitalista; es decir, ni las guerras ni las políticas internacionales pueden verse como algo externo al capitalismo como sistema económico mundial. Los períodos de hegemonía en la política de las grandes potencias corresponden a períodos de consolidación de modelos económicos particularmente prósperos y productivos (el modelo neerlandés de mediados del siglo XVII , que combina la libertad económica doméstica con un comercio mundial estrictamente controlado y

El análisis más importante sobre la desigualdad del desarrollo espacial es el que presenta Harvey (1999). 
fuertemente armado; el modelo inglés, a mediados del siglo XIX, de industrialización doméstica y libre comercio; y el modelo estadounidense de las décadas posteriores a la Segunda Guerra Mundial, de multinacionales, producción en masa y gestión económica keynesiana). Por el contrario, los períodos en los que el país económicamente dominante perdía su ventaja, en gran medida porque las potencias emergentes tenían éxito copiando sus técnicas, estaban marcados por rivalidades internacionales más intensas y más fuertes (entre Países Bajos, Inglaterra y Francia a finales de los siglos XVII y XVIII; entre Inglaterra, Alemania, Francia y Estados Unidos a finales del siglo XIX y principios del XX; y entre Estados Unidos y China a principios del siglo $\mathrm{XXI}$ ), rivalidades que históricamente han desatado guerras destructivas. En resumen, Arrighi (1994) demostró que la expansión a largo plazo del capitalismo por toda la superficie mundial, así como el desarrollo económico a corto o mediano plazo siguen un patrón fundamentalmente cíclico.

\section{Historias del capitalismo}

Aquí solo he esbozado algunas de las dinámicas históricas específicas que definen el capitalismo; dinámicas que, de manera azarosa, produjeron un sistema de relaciones sociales extrañamente robusto y poderoso en el cual estamos inmersos todos. Solo me quedan unas cuantas líneas para decir qué implican estas dinámicas para la escritura de las historias del capitalismo.

En primer lugar, tenemos que darnos cuenta de que la "historia" —en el sentido de una disciplina intelectual que intenta explicar cómo contribuyen los acontecimientos del pasado en importantes transformaciones en las sociedades humanas - es un aspecto del nuevo sentido dinámico de la temporalidad que engendró el desarrollo capitalista. El intento mismo de escribir historias sobre el capitalismo tiene lugar bajo el manto de los efectos temporales del propio capitalismo.

En segundo lugar, la historia del capitalismo no puede limitarse a la historia económica ni a la economía política. La dinámica intrínseca del capitalismo no es solamente un asunto económico: entre múltiples dimensiones, se halla en las formas de hegemonía político-militar, en las complejas esferas culturales y psicológicas del deseo del consumidor y de la ilimitada codicia capitalista o en instituciones de educación científica. Y las dinámicas intrínsecas del capitalismo se manifiestan en la práctica en cada aspecto de la vida social: en la literatura, en el comportamiento demográfico, en el urbanismo, en las relaciones entre colonizadores y colonizados, en la especulación filosófica, en los patrones de sexualidad, en las relaciones laborales, en las ejecuciones musicales, etc. Las historias del capitalismo son y deben seguir siendo múltiples y heterogéneas. 
En tercer lugar, aceptar que el capitalismo es una época no implica volver a caer en las temporalidades teleológicas de las teorías de modernización ni en un determinismo marxista superficial. El sistema capitalista de producción e intercambio sostiene en su núcleo una dinámica ilimitada de acumulación de capital, esto es lo que lo hace tan extraordinario. Pero esta dinámica no debe entenderse como algo teleológico, ya que no tiene ningún objetivo trascendental más allá de la acumulación para la acumulación, lo cual es insustancial y, en últimas, destructivo. Además, la dinámica direccional del capitalismo debe entenderse como un producto histórico destinado a desaparecer: es una época, es solo una época.

En cuarto lugar, el hecho de que el capitalismo tenga incorporada una direccionalidad no implica que la temporalidad ordinaria, contingente y azarosa deje de funcionar en la era capitalista. Las temporalidades de la política, el pensamiento, la guerra, la vida familiar, la diplomacia, los movimientos sociales o la existencia cotidiana están más que nunca constituidas por acontecimientos contingentes y consecuencias trascendentales. La dinámica específica del capitalismo ejerce presiones y restricciones direccionales sobre el flujo de los acontecimientos en todas las esferas sociales. Cuáles son estas presiones y restricciones o qué efectos tienen, no puede deducirse simplemente a partir de alguna teoría previa del capitalismo; una ciencia histórica digna de ese nombre debe descubrirlas y estudiarlas cuidadosamente.

En quinto y último lugar, el hecho de que el capitalismo incorpore una direccionalidad tampoco implica que el núcleo económico del capitalismo esté libre de cualquier situación contingente o azarosa. De hecho, el capitalismo puede considerarse como una máquina diseñada especialmente para la producción frenética de acontecimientos (genera inventos, compras excesivas, lanzamientos de productos, campañas publicitarias y cotizaciones en bolsa, al igual que quiebras, burbujas, crisis y luchas obreras). El metabolismo expansionista del capital tiende a absorber más rápidamente los acontecimientos característicos del núcleo económico del capitalismo que los acontecimientos que están más alejados de él. Sin embargo, no hay garantía de que dicha absorción funcione de forma automática o indefinida. Hay contingencias producidas por el propio capitalismo, contingencias de otros aspectos de la vida moderna y nuevas contingencias que surgen de las contradicciones entre la infinita expansión del capitalismo y los estrictos límites que imponen los sistemas ambientales de la Tierra. Estas contingencias combinadas hacen más probable una transformación del capitalismo hacia un futuro poscapitalista. Con un poco de suerte, coraje político, vigilancia y trabajo duro -especialmente por parte de los historiadores con una sólida formación en ciencias sociales-, los recursos críticos y científicos con que nos ha dotado 
el capitalismo podrían permitirnos construir un futuro poscapitalista mejor que nuestro presente capitalista.

\section{Referencias}

Arrighi, G. (1994). The Long Twentieth Century: Money, Power, and the Origins of Our Times. Verso.

Aston, T. H. y Philpin, C. H. E. (Eds.). (1985). The Brenner Debate: Agrarian Class Structure and Economic Development in Pre-Industrial Europe. Cambridge University Press.

Berman, M. (1982). All That Is Solid Melts into Air: The Experience of Modernity. Simon and Schuster.

Bourguignon, F. y Morrison, C. (2002). Inequality among world citizens: 1820-1992. American Economic Review, 92(4), 727-44.

Chrakrabarty, D. (2009). The climate of history: Four theses. Critical Inquiry, 35, 197-222.

De Vries, J. (2008). The Industrious Revolution: Consumer Behavior and the Household Economy, 1650 to the Present. Cambridge University Press.

Floud, R., Fogel, R. W., Harris, B. y Hong, S. C. (2011). The Changing Body: Health, Nutrition, and Human Development in the Western World since 1700. Cambridge University Press.

Fogel, R. W. (2004). The Escape from Hunger and Premature Death, 1700-2100: Europe, America, and the Third World. Cambridge University Press.

Gramsci, A. (1971). Selections from the Prison Notebooks. En Q. Hoare y G. Nowell Smith (eds. y trads.). International Publishers.

Harvey, D. (1999). The Limits to Capital. Verso.

Koselleck, R. (2002). The eighteenth century as the beginning of modernity. En T. S. Presner; K. Behnke y J. Welge (trads.), Prólogo de H. White, The Practice of Conceptual History: Timing History, Spacing Concepts (pp. 154-69). Stanford University Press.

Le Roy Ladurie, E. (1974), L'histoire immobile. Annales: Économies, Sociétés, Civilisations, 29(3), 673-92.

Marx, K. (1977). Capital (vol. 1). B. Fowkes (trad.). Vintage Books.

Marx, K. y Engels, F. (1962). Manifesto of the Communist Party. Selected Works, (vol. 1). Foreign Languages Publishing House.

North, D. C. (1981). Structure and Change in Economic History. Norton.

North, D. C. (1990). Institutions, Institutional Change, and Economic Performance. Cambridge University Press.

North D. C. y Thomas, R. P. (1973). The Rise of the Western World: A New Economic History. Cambridge University Press.

Pomeranz, K. (2000). The Great Divergence: China, Europe, and the Making of the Modern World Economy. Princeton University Press.

Postone, M. (1993). Time, Labor, and Social Domination: A Reinterpretation of Marx's Critical Theory. Cambridge University Press.

Schumpeter, J. A. (1950). Capitalism, Socialism, and Democracy (3. ${ }^{\mathrm{a}}$ ed.). Harper and Row. 
Sewell, W. H. Jr. (1980). Work and Revolution: The Language of Labor from the Old Regime to the Revolution of 1848. Cambridge University Press.

Sewell, W. H. Jr. (1994). A Rhetoric of Bourgeois Revolution: The Abbé Sieyes and "What Is the Third Estate?". Duke University Press.

Sewell, W. H. Jr. (2005). Logics of History: Social Theory and Social Transformation. University of Chicago Press.

Sewell, W. H. Jr. (2008). The temporalities of capitalism. Socio-Economic Review, 6(3), 517-37.

Sewell, W. H. Jr. (2010). The rise of capitalism and the empire of fashion in eighteenth-century France. Past and Present, 206(1), 81-120.

Sewell, W. H. Jr. (2012). Economic crises and the shape of modern history. Public Culture, 24(2), 303-27.

Sewell, W. H. Jr. (2019). L'époque capitaliste. Tracés. Revue de Sciences humaines [En ligne], (36), 169182. URL: http://journals.openedition.org/traces/9648

Wallerstein, I. (1974). The Modern World-System. Vol. 1, Capitalist Agriculture and the Origins of the European World-Economy in the Sixteenth Century. Academic Press.

Weber, M. (1976). The Protestant Ethic and the Spirit of Capitalism. (T. Parsons, trad.; A. Giddens, introducción). Charles Scribner's Sons.

Wilson, A. M. (1972). Diderot. Oxford University Press. 